\title{
INTESTINAL PARASITES IN PATIENTS HAVING HAEMATOLOGICAL MALIGNANCIES
}

\author{
Sneha Phulsunge1, Avani Koticha², Shivani Shinde ${ }^{3}$, Preeti Mehta ${ }^{4}$ \\ ${ }^{1}$ Senior Resident, Department of Microbiology, Seth G. S. Medical College \& KEM Hospital, Parel, Mumbai. \\ ${ }^{2}$ Additional Professor, Department of Microbiology, Seth G. S. Medical College \& KEM Hospital, Parel, Mumbai. \\ ${ }^{3}$ Assistant Professor, Department of Microbiology, Seth G. S. Medical College \& KEM Hospital, Parel, Mumbai. \\ ${ }^{4}$ Professor \& HOD, Department of Microbiology, Seth G. S. Medical College \& KEM Hospital, Parel, Mumbai.
}

\begin{abstract}
BACKGROUND

Haematological malignancies like leukaemia, lymphoma and myeloma originate in the bone marrow, lymph nodes which may be acute and chronic. These patients receive immunosuppressive agents, which put them at increased risk of infections, especially due to intestinal parasites. Parasitic infections if not diagnosed early may give rise to morbidity and mortality, more so if these infections remain asymptomatic, such patients pose a threat to others in the community. Hence, early diagnosis of intestinal parasitic infections is mandatory.
\end{abstract}

\section{AIMS}

To determine the prevalence of intestinal parasitic infections in patients having haematological malignancy.

\section{SETTINGS AND DESIGN}

125 patients in the age group of 3 to 60 years diagnosed to have haematological malignancies receiving chemotherapy were recruited for the present study and were instructed to bring three fresh stool specimens on non-consecutive days. The study was carried out for one year at a tertiary care multi-speciality teaching institute.

\section{MATERIAL AND METHODS}

Gross and microscopic examination, concentration technique of Formol ether sedimentation and saturated common salt solution were used. Permanent staining technique using Trichrome stain and Modified acid fast staining technique were performed on all the stool samples.

\section{RESULTS}

Overall prevalence of intestinal parasites detected was 54.4\%. Intestinal parasites were detected in 68.75\%, 54.85\%, 46.88\% and $46.6 \%$ of patients having Acute Lymphoblastic Leukaemia (ALL), Acute Myeloid Leukaemia (AML), Multiple myeloma (MM) and Lymphoma respectively. Protozoan parasites, Giardia lamblia were predominant in the list. Mixed infections were not seen. Coccidian intestinal parasites were not detected.

\section{CONCLUSION}

Screening of stool specimens of patients having haematological malignancies at regular interval to detect the presence of intestinal parasites should be made a mandatory practice.

\section{KEYWORDS}

Intestinal Parasites, Leukaemia, Lymphoma, Haematological Malignancies.

HOW TO CITE THIS ARTICLE: Phulsunge $S$, Koticha A, Shinde $S$, et al. Intestinal parasites in patients having haematological malignancies. J. Evolution Med. Dent. Sci. 2016;5(31):1613-1617, DOI: 10.14260/jemds/2016/380

\section{INTRODUCTION}

Haematological malignancies originate in the bone marrow and lymph nodes which include leukaemia, lymphoma, and myeloma. ${ }^{1}$ Patients suffering from haematological malignancies face a double-edged sword of immunosuppression due to the disease process and treatment given to them such as steroids and anti-neoplastic regimens.

With this view, a prospective study was designed to determine the prevalence of intestinal parasites in patients having haematological malignancies receiving chemotherapy.

Financial or Other, Competing Interest: None.

Submission 28-02-2016, Peer Review 23-03-2016,

Acceptance 29-03-2016, Published 15-04-2016.

Corresponding Author:

Dr. Avani Koticha,

Guru Krupa, $1^{\text {st }}$ Floor,

Above Standard Chartered Bank,

65-F, Linking Road, Santacruz (W),

Mumbai-400054, India.

E-mail: avani61koticha@gmail.com

DOI: $10.14260 /$ jemds $/ 2016 / 380$
This makes them more vulnerable leading to morbidity and mortality.2,3 In the past few years, major advances in treatment regimens have allowed cancer patients to live a prolonged and quality life, creating an adverse impact on the host defense mechanisms and have placed the patients at risk for infectious complications. ${ }^{3,4}$ The infectious complications are related to bacterial, viral, fungal and parasitic diseases. ${ }^{5}$ Among these, intestinal parasites still remain a major health concern in immunosuppressed patients.

Very few studies have been carried out with respect to the prevalence of intestinal parasites in patients having haematological malignancies. Some of these are done by Rudrapatna et al.(3) Tasova et al.(6) and Aksoy $U$ et al. ${ }^{7}$ Intestinal parasitic infections if diagnosed early in the disease process may help to reduce morbidity, mortality among patients ensuring better quality of life and prevent spread in the community.

\section{MATERIALS AND METHODS}

After obtaining Institutional Ethics Committee permission, a total of 125 patients in the age group of 3 to 60 years 
diagnosed to have haematological malignancies like Acute Lymphoblastic Leukaemia (ALL), Acute Myeloid Leukaemia (AML), Multiple Myeloma (MM), Hodgkin's and NonHodgkin's Lymphoma receiving chemotherapy were recruited for the present study. The study was carried out for one year at a tertiary care multi-speciality teaching institute. Detailed clinical history was noted after taking written informed consent. The patients who were on anti-parasitic treatment for the last one month as well as those who were receiving only palliative treatment were excluded from the present study.

The patients were instructed to submit three fresh stool specimens in leak proof, dry, wide mouth plastic containers on non-consecutive days, which were processed as per the standard procedure with respect to gross and microscopic examination. Concentration technique of Formol ether sedimentation and saturated common salt solution were used. Permanent staining technique using Trichrome stain and Modified acid fast staining technique were performed. ${ }^{8}$ The results of all the tests were observed, interpreted, recorded and statistically analysed using Chi square test where applicable. P value $<0.05$ was considered as significant. Appropriate treatment was administered to the patient based on findings of stool examination.

\section{RESULTS OF THE PRESENT STUDY ARE SHOWN IN THE FORM OF TABLES}

\begin{tabular}{|c|c|c|c|c|c|c|c|c|c|c|c|c|c|c|}
\hline \multirow[b]{2}{*}{$\begin{array}{l}\text { Age in } \\
\text { Years }\end{array}$} & \multirow[b]{2}{*}{$\begin{array}{l}\text { Total } \\
\text { Males }\end{array}$} & \multicolumn{5}{|c|}{ Parasites Detected } & \multirow[b]{2}{*}{$\begin{array}{c}\text { Total } \\
\text { Females }\end{array}$} & \multicolumn{5}{|c|}{ Parasites Detected } & \multirow[b]{2}{*}{$\begin{array}{c}\text { Total } \\
\text { Patients }\end{array}$} & \multirow[b]{2}{*}{$\begin{array}{c}\text { Total } \\
\text { Parasites }\end{array}$} \\
\hline & & Eh & Gl & $\mathbf{B h}$ & Al & Ad & & Eh & Gl & Bh & Al & Ad & & \\
\hline $3-10$ & 18 & 4 & 6 & 2 & 1 & 0 & 9 & 0 & 3 & 2 & 0 & 0 & 27 & 18 \\
\hline $11-20$ & 1 & 0 & 1 & 0 & 0 & 0 & 0 & 0 & 0 & 0 & 0 & 0 & 1 & 1 \\
\hline $21-30$ & 1 & 1 & 0 & 0 & 0 & 0 & 1 & 0 & 0 & 1 & 0 & 0 & 2 & 2 \\
\hline $31-40$ & 9 & 1 & 4 & 0 & 0 & 1 & 4 & 1 & 0 & 0 & 1 & 0 & 13 & 8 \\
\hline $41-50$ & 26 & 6 & 2 & 2 & 0 & 0 & 14 & 2 & 2 & 3 & 0 & 0 & 40 & 17 \\
\hline $51-60$ & 28 & 6 & 3 & 3 & 1 & 0 & 14 & 0 & 3 & 5 & 0 & 1 & 42 & 22 \\
\hline Total & $83(66.4 \%)$ & 18 & 16 & 7 & 2 & 1 & $\begin{array}{c}42 \\
(33.6 \%)\end{array}$ & 3 & 8 & 1 & 1 & 1 & $\begin{array}{c}125 \\
(100 \%)\end{array}$ & $\begin{array}{c}68 \\
(54.4 \%)\end{array}$ \\
\hline
\end{tabular}

Eh-Entamoeba histolytica/dispar, Gl- Giardia lamblia, Bh- Blastocystis hominis.

Al- Ascaris lumbricoides, Ad- Ancylostoma duodenale.

\begin{tabular}{|c|c|c|c|c|c|c|c|c|c|c|}
\hline & & \multicolumn{3}{|c|}{ Parasites Detected } & \multicolumn{2}{c|}{ Parasites Detected } & Total \\
\hline $\begin{array}{c}\text { Age in } \\
\text { Years }\end{array}$ & $\begin{array}{c}\text { Total } \\
\text { Males }\end{array}$ & Eh & Gl & Bh & Al & $\begin{array}{c}\text { Females } \\
\text { Gl }\end{array}$ & Bh & $\begin{array}{c}\text { Total } \\
\text { Patients }\end{array}$ & $\begin{array}{c}\text { Total } \\
\text { Parasites }\end{array}$ \\
\hline $3-10$ & 18 & 4 & 6 & 2 & 1 & 9 & 3 & 2 & 27 & 18 \\
\hline $11-20$ & 0 & 0 & 0 & 0 & 0 & 0 & 0 & 0 & 0 & 0 \\
\hline $21-30$ & 0 & 0 & 0 & 0 & 0 & 0 & 0 & 0 & 0 & 0 \\
\hline $31-40$ & 0 & 0 & 0 & 0 & 0 & 0 & 0 & 0 & 0 & 0 \\
\hline $41-50$ & 2 & 1 & 0 & 0 & 0 & 1 & 0 & 1 & 3 & 2 \\
\hline $51-60$ & 1 & 1 & 0 & 0 & 0 & 1 & 0 & 1 & 2 & 2 \\
\hline Total & $\mathbf{2 1}$ & $\mathbf{6}$ & $\mathbf{6}$ & $\mathbf{2}$ & $\mathbf{1}$ & $\mathbf{1 1}$ & $\mathbf{3}$ & $\mathbf{4}$ & $\mathbf{3 2}$ \\
\hline
\end{tabular}

\begin{tabular}{|c|c|c|c|c|c|c|c|c|c|}
\hline \multirow[b]{2}{*}{$\begin{array}{l}\text { Age in } \\
\text { Years }\end{array}$} & \multirow[b]{2}{*}{ Males } & \multicolumn{3}{|c|}{ Parasites Detected } & \multirow[b]{2}{*}{ Females } & \multicolumn{2}{|c|}{$\begin{array}{l}\text { Parasites } \\
\text { Detected }\end{array}$} & \multirow[b]{2}{*}{ Total Patients } & \multirow[b]{2}{*}{$\begin{array}{c}\text { Total } \\
\text { Parasites } \\
\end{array}$} \\
\hline & & Al & Eh & Gl & & Eh & Bh & & \\
\hline $3-10$ & 0 & 0 & 0 & 0 & 0 & 0 & 0 & 0 & 0 \\
\hline $11-20$ & 1 & 0 & 0 & 1 & 0 & 0 & 0 & 1 & 1 \\
\hline $21-30$ & 1 & 0 & 1 & 0 & 1 & 0 & 1 & 2 & 1 \\
\hline $31-40$ & 3 & 0 & 1 & 2 & 2 & 1 & 0 & 5 & 4 \\
\hline $41-50$ & 8 & 0 & 2 & 1 & 4 & 2 & 0 & 12 & 5 \\
\hline $51-60$ & 7 & 1 & 0 & 2 & 4 & 0 & 2 & 11 & 5 \\
\hline Total & 20 & 1 & 4 & 6 & 11 & 3 & 3 & 31 & $\begin{array}{c}17 \\
(54.85 \%)\end{array}$ \\
\hline
\end{tabular}




\begin{tabular}{|c|c|c|c|c|c|c|c|c|c|}
\hline \multirow[b]{2}{*}{$\begin{array}{l}\text { Age in } \\
\text { Years }\end{array}$} & \multirow[b]{2}{*}{ Males } & \multicolumn{3}{|c|}{ Parasites Detected } & \multirow[b]{2}{*}{ Females } & \multicolumn{2}{|c|}{ Parasites Detected } & \multirow[b]{2}{*}{$\begin{array}{c}\text { Total } \\
\text { Patients }\end{array}$} & \multirow[b]{2}{*}{$\begin{array}{c}\text { Total } \\
\text { Parasites }\end{array}$} \\
\hline & & Bh & Eh & Ad & & Ad & Gl & & \\
\hline $3-10$ & 0 & 0 & 0 & 0 & 0 & 0 & 0 & 0 & 0 \\
\hline $11-20$ & 0 & 0 & 0 & 0 & 0 & 0 & 0 & 0 & 0 \\
\hline $21-30$ & 0 & 0 & 0 & 0 & 0 & 0 & 0 & 0 & 0 \\
\hline $31-40$ & 2 & 0 & 0 & 1 & 0 & 0 & 0 & 2 & 1 \\
\hline $41-50$ & 8 & 1 & 1 & 0 & 6 & 0 & 2 & 14 & 4 \\
\hline $51-60$ & 10 & 3 & 3 & 0 & 6 & 1 & 3 & 16 & 10 \\
\hline Total & 20 & 4 & 4 & 1 & 12 & 1 & 5 & 32 & $\begin{array}{c}15 \\
(46.88 \%)\end{array}$ \\
\hline
\end{tabular}

\begin{tabular}{|c|c|c|c|c|c|c|c|c|c|}
\hline $\begin{array}{l}\text { Age in } \\
\text { Years }\end{array}$ & Males & Eh & Gl & Bh & Females & Al & Bh & $\begin{array}{c}\text { Total } \\
\text { Patients }\end{array}$ & $\begin{array}{c}\text { Total } \\
\text { Parasites }\end{array}$ \\
\hline $3-10$ & 0 & 0 & 0 & 0 & 0 & 0 & 0 & 0 & 0 \\
\hline $11-20$ & 0 & 0 & 0 & 0 & 0 & 0 & 0 & 0 & 0 \\
\hline $21-30$ & 0 & 0 & 0 & 0 & 0 & 0 & 0 & 0 & 0 \\
\hline $31-40$ & 4 & 0 & 2 & 0 & 2 & 1 & 0 & 6 & 3 \\
\hline $41-50$ & 8 & 2 & 1 & 1 & 3 & 0 & 2 & 11 & 6 \\
\hline $51-60$ & 10 & 2 & 1 & 0 & 3 & 0 & 2 & 13 & 5 \\
\hline Total & 22 & 4 & 4 & 1 & 8 & 1 & 4 & 30 & $14(46.67 \%)$ \\
\hline
\end{tabular}

\section{DISCUSSION}

Haematological malignancies are neoplastic proliferation of white blood cells, i.e. leukaemias and lymphomas. Leukaemias have been classified on the basis of cell types predominantly involved into myeloid and lymphoid, on the natural history of disease into acute and chronic.(9) Myeloid leukaemia includes Acute Myeloid Leukaemia (AML), Chronic Myeloid Leukaemia (CML) and Lymphoid Leukaemia includes Chronic Lymphocytic Leukaemia (CLL), Acute Lymphoblastic Leukaemia (ALL). Lymphomas include Hodgkin's and nonHodgkin's lymphoma. Plasma cell tumour includes Multiple Myeloma (MM).(1,9,10)

The institution where this study was conducted, chemotherapy including reinduction program in the form of treatment cycles is repeatedly continued for a period of 6-10 months. These cycles go on without a break. Immunosuppression is not thus tapered off for these patients for a considerable length of time. Due to this reason, correlation between prevalence of intestinal parasitic infections and the time elapsed since chemotherapy could not be studied. There is no such data available in literature pertaining to intestinal parasitic infections and the time elapsed since chemotherapy in patients having haematological malignancies.

There were 125 patients having haematological malignancies, of which $66.4 \%(83 / 125)$ were males and $33.6 \%(42 / 125)$ females. The overall prevalence of intestinal parasites of the present study is $54.4 \%$. A study done by Rudrapatna JS et al.(3) have reported the prevalence of intestinal parasites in patients having haematological malignancies to be $16.5 \%$, whereas that reported by Botero $\mathrm{JH}$ et al. and Umit Aksoy et al. is $32.6 \%$ and $42 \%$ respectively.(2,7) The reasons for the high prevalence reported in the present study could be attributed to the geographical distribution of the parasites.
$68.75 \%$ patients of Acute Lymphoblastic Leukaemia (ALL) had intestinal parasites of which maximum prevalence was seen in the age group of 3-10 years. Among the protozoan parasites in the male patients, Entamoeba histolytica/dispar and Giardia lamblia were seen in 6 cases each. Blastocystis hominis was seen in 2 and among the intestinal helminths, Ascaris lumbricoides was seen in 1 . Among the female patients, Giardia lamblia was detected in 3 and Blastocystis hominis in 4.

Intestinal parasites were detected in $54.85 \%$ patients having Acute Myeloid Leukaemia (AML). High prevalence of intestinal parasites was noted in patients between 41-50 and 51-60 years of age. Among the protozoan parasites in the male patients, Entamoeba histolytica/dispar was seen in 4, Giardia lamblia in 6, Ascaris lumbricoides was detected in 1. Among the female patients, Entamoeba histolytica/dispar was seen in 3, Blastocystis hominis in 3 patients.

Intestinal parasites were detected in $46.88 \%$ patients of Multiple Myeloma (MM). Prevalence of intestinal parasites was maximally seen in patients between 51-60 years. Among the protozoan parasites, Entamoeba histolytica/dispar and Blastocystis hominis were detected in 4 and among the helminths, Ancylostoma duodenale in 1 in male and among females Giardia lamblia in 5 and Ancylostoma duodenale in 1. Intestinal parasites were detected in $46.6 \%$ patients having lymphomas of which maximum was detected in the age group of 41-50 years. Among the protozoan parasites, Blastocystis hominis was detected in 1, Giardia lamblia in 4, Entamoeba histolytica/dispar in 4 among males. Blastocystis hominis was detected in 4 Giardia lamblia in 1 among females.

Of $101 / 125(80.8 \%)$ symptomatic patients, parasites were detected in $63(62.37 \%)$, whereas 5 patients demonstrated parasites out of 24 asymptomatic patients (20.8\%) $(\mathrm{p}=0.0002)$.

The detection rate of intestinal parasites was significantly higher in symptomatic patients than in 
asymptomatic patients. However, $20.8 \%$ parasites detected in asymptomatic patients is still alarming.

The carriage of intestinal parasites in asymptomatic cases poses a threat to the patient as well as to the community, especially in areas of poor personal hygiene. The patients having haematological malignancies on chemotherapy are frequently asymptomatic because immunosuppression delays inflammatory response till the parasitic load becomes high. Parasites reported in asymptomatic patients are mainly protozoan parasites, namely Giardia lamblia, Entamoeba histolytica/dispar, Blastocystis hominis. They are transmitted faeco-orally and pose a great threat to the others including children, especially when there is no insight into the mode of infection of these parasites and poor hygienic condition. Of these 5 specimens, three revealed Giardia lamblia, 1 revealed Blastocystis hominis and 1 revealed Entamoeba histolytica/dispar.

In the present study, protozoan parasites predominated the list. Giardia lamblia was the predominant protozoan with the prevalence of $19.2 \%$ followed by Entamoeba histolytica/dispar, Blastocystis hominis, Ascaris lumbricoides and Ancylostoma duodenale having their prevalence to be $16.8 \%, 14.4 \%, 2.4 \%, 1.6 \%$, respectively. The transmission of protozoan parasites occur via fecal-oral route, either directly from an infected person who has poor personal hygiene or indirectly by eating or drinking fecally contaminated food and water.

Cysts of Giardia lamblia can survive on inanimate objects for long and as low as 8-10 cysts can initiate an infection. This invariably results in faeco-oral transmission of the parasite with great ease. Acute giardiasis usually resolves within a few days and chronic giardiasis occurs, which may last for more than 2 years and cause intermittent diarrhea.(11)

There is difficulty in determining the clinical significance of Entamoeba histolytica in stool as its cyst is similar to Entamoeba dispar morphologically and hence cannot be differentiated. As per the literature about $90 \%$ of Entamoeba histolytica reported is actually Entamoeba dispar, which is known to be non-pathogenic. Hence to differentiate the two, molecular analysis or ELISA test needs to be performed on stool specimens. However, these tests are not feasible in routine parasitology laboratories, careful history of the patient needs to be taken and if stool specimen is found to have Entamoeba histolytica, treatment for the same needs to be initiated and patient should be observed for relief of symptoms.

Higher prevalence of Entamoeba histolytica and Giardia lamblia in our study may be explained by the fact that there is favourable climatic condition for survival of cysts outside the human host and factors contributing to its transmission are also favourable.(12) According to the literature, Blastocystis hominis is no longer a commensal, but a potential pathogen causing diarrhoea.(13-15) It has been shown to cause infection in immunocompromised patients, such as renal transplant patients and those having HIV and haematological malignancy.

The prevalence of Blastocystis hominis reported in the present study is $14.4 \%$. Almost similar prevalence of $13 \%$ has been reported by Tasova Y et al. in 2000.(6) in their study.

Higher prevalence of $26 \%$ has been reported by Aksoy $U$ et al. in 2003.(7) Low prevalence of intestinal helminths in our study can be attributed to certain environmental factors.
Larvae of Ascaris lumbricoides and Ancylostoma duodenale develop only in moist soils; the high temperature does not allow the eggs of parasites to survive in dry soil for sufficient period for their growth and maturation. Roads are cemented due to industrialization and urbanization and there are less chances of soil being contaminated with faeces and transmission of this soil transmitted nematode.(16) Also the practice of wearing foot wears has generally reduced the transmission of hook worms larvae. Other intestinal helminths such as Strongyloides stercoralis, Trichuris trichiura, Enterobius vermicularis were not reported in this study.

Both the concentration techniques namely, saturated salt solution and formol-ether sedimentation were found to be equally effective in detecting parasites in the present study as all intestinal helminths were detected using saturated salt solution and all the protozoan parasites were seen when formol-ether sedimentation technique was used. We could demonstrate all the protozoan parasites by Trichrome staining technique; however, we could not demonstrate any coccidian intestinal parasite like Cryptosporidium, Cyclospora, and Cystoisospora by Modified Ziehl-Neelsen staining of stool. Mixed infections were not reported in the present study.

Of 125 patients, 51 patients submitted only one stool specimen, 74 patients submitted two stool specimens and the third specimen was not submitted by any patient. Out of the 51 patients who submitted only one stool specimen, intestinal parasites were detected in stool specimens of 17 patients (33.33\%), whereas of 74 patients who submitted two specimens, intestinal parasites were detected in the first stool specimen of 21 patients $(28.37 \%)$ and in the second stool specimen of an additional 9 patients. Hence, intestinal parasites were detected in a total of 51 out of 74 patients (68.91\%) when two stool specimens were examined. Thus, there is an increase in sensitivity of detection of intestinal parasites when two stool specimens were examined instead of one.

All the patients who showed the presence of intestinal parasitic infections were treated; however, repeat examination of stool for demonstrating parasitological cure could not be carried out. Usually, patients having haematological malignancies are not routinely screened for the presence of intestinal parasitic infections. These patients may harbour the intestinal parasites and remain asymptomatic for a long duration and may become symptomatic leading to profuse diarrhoea and increase in morbidity and mortality. Hence, periodic screening of stool specimens at regular intervals of these patients for intestinal parasites is mandatory.

\section{REFERENCES}

1. Kumar V. Haematopoetic and lymphoid system. In: Robbins basic pathology philadelphia: patricia tannian, 2013; $9^{\text {th }}$ ed.

2. Botero JH, Castaño A, Montoya MN, et al. A preliminary study of the prevalence of intestinal parasites in immunocompromised patients with and without gastrointestinal manifestations. Rev Inst Med Trop Sao Paulo 2003;45(4):197-200.

3. Rudrapatna JS, Kumar V, Sridhar H. Intestinal parasitic infections in patients with malignancy. J Diarrhoeal Dis Res 1997;15(2):71-4. 
4. Freifeld AG. Infectious complications in the immunocompromised host the antimicrobial armamentarium. Haematol Oncol Clin North Am 1993;7(4):813-39.

5. Zembower TR. Epidemiology of infections in cancer patients. Infections complication in cancer patients 2014;161:43-89.

6. Tașova Y, Sahin B, Koltaș S, et al. Clinical significance and frequency of blastocystishominis in Turkish patients with haematological malignancy. Acta Med Okayama 2000;54(3):133-6.

7. Aksoy U, Erbay A, Akisu C, et al. Intestinal parasites in children with neoplasms. Turk J Pediatr 2003;45(2):12932.

8. Garcia LS. Diagnostic medical parasitology. Washington (DC): ASM Press, 2007; 5th ed.

9. Mohan H. Disorder of leucocytes \& lymphoreticular tissues. In: textbook of pathology, Jaypee Brothers medical publishers, 2010; $6^{\text {th }}$ eds:342-89.

10. Wetzler M, Marcucci G, Bloomfield CD. Acute and chronic myeloid leukaemia. In: Longo DC Harrison's principles of internal medicine, $18^{\text {th }}$ edition. Chapter 109 , Vol 1:pg 90518.
11. Wolfe MS. Giardiasis. Clin Microbiol Rev 1992;5(1):93100.

12. Fotedar R, Stark D, Beebe N, et al. Laboratory diagnostic techniques for entamoeba species. Clin Microbiol Rev 2007;20(3):511-32.

13. Scanlan PD. Blastocystis: past pitfalls and future perspectives. Trends parasitol 2012;28(8):327-34.

14. Eida AM, Eida MM. Identification of blastocystis hominis in patients with irritable bowel syndrome using microscopy and culture compared to PCR. Parasitologists United Journal 2008;1(2):87-92.

15. Sukthana Y. Is blastocystis hominis a human pathogenic protozoan? J Trop Med Parasitol 2001;24(1):16-22.

16. Schmidlin T, Hurlimann E, Silue KD, et al. Effects of hygiene and defecation behavior on helminths and intestinal protozoa infections in taabo, cote d'Ivoire. PLoS One jun, 2013. [Internet] 2014;8(6). [about 12pp] Available from: http://www.plosone.org/article/info\%3Adoi\%2F10.137 1\%2Fjournal.pone.0065722. 